\title{
Ovarian Dermoid Cyst with Sebaceous
} Carcinoma

National Cancer Institute

\section{Source}

National Cancer Institute. Ovarian Dermoid Cyst with Sebaceous Carcinoma. NCI

Thesaurus. Code C40004.

A secondary sebaceous carcinoma that has developed in an ovarian dermoid cyst. 